\title{
IMPROVING COMMITMENT TO AGREEMENTS: THE ROLE OF GROUP DECISION-MAKING METHODS IN THE PERCEPTION OF SENSE OF JUSTICE AND SATISFACTION AS COMMITMENT PREDICTORS
}

\author{
Vanessa Coimbra Ziotti ${ }^{1}$ and Alexandre Bevilacqua Leoneti ${ }^{2 *}$
}

Received October 23, 2019 / Accepted May 25, 2020

\begin{abstract}
The objective of this study was to evaluate the chances of commitment in group decision making process, modeled by a multicriteria method based on game theory and its evaluation in relation to the satisfaction and sense of justice of the players. We hypothesized that mathematical methods may favor group decision-making, reflecting higher levels of sense of justice and satisfaction and consequently greater chances of commitment to the agreements made. By means of 75 simulations, with five volunteers each, the hypotheses of this study were confirmed, which include the affirmation that the commitment in group decision making can be increased by the use of a method to support group decision making and, consequently, that the sense of justice and satisfaction will be greater when agreements are supported by some sort of mathematical method.
\end{abstract}

Keywords: satisfaction, justice sense, game theory.

\section{INTRODUCTION}

Group decision-making requires not only a structured process (Keeney, 1982; Bazerman \& Moore, 2012), but also the implementation of the decision, since the commitment to a group decision can be broken whether individuals are not satisfied with the agreement (Harsanyi, 1977) or do not perceive justice in the decision-making process (Rawls, 1971). Nevertheless, agreement implementation is a subject that has been neglected, despite its practical importance (Mislin et al., 2011).

The perception of justice is an important antecedent of commitment to the implementation of agreements, also known as contracts (Filenga \& Siqueira, 2006; Li \& Cropanzano, 2009; Mislin et al., 2011; Cropanzano et al., 2015; Park et al., 2016; Druckman \& Wagner, 2017; Saha \& Kumar, 2017). When an individual perceives that is not benefited by a solution proposed in an

\footnotetext{
*Corresponding author

${ }^{1}$ Grupo de Pesquisa em Ciências da Decisão, Faculdade de Economia, Administração e Contabilidade, Universidade de São Paulo, Ribeirão Preto, Brazil - E-mail: vanessaziotti@gmail.com - https://orcid.org/0000-0001-5863-352X

${ }^{2}$ Grupo de Pesquisa em Ciências da Decisão, Faculdade de Economia, Administração e Contabilidade, Universidade de São Paulo, Ribeirão Preto, Brazil - E-mail: ableoneti@usp.br - https://orcid.org/0000-0002-0744-8866
} 
agreement reached by the group, and that, on the contrary, the breach of contract is what would bring him/her most benefits, then it is expected that the individual does not honor the contract (Li \& Cropanzano, 2009; Camerer, 2011). Moore (2007) states that the unbalanced payoffs of members of a decision group is a good indicator for breach of contract, which is the case even when an individual choose to reduce the maximization of its own gains (Charness \& Sutter, 2012; Camerer, 2011). When there is evidence that the decision will not be maintained, lower levels of satisfaction and sense of justice can be noticed (Filenga and Siqueira 2006).

The perception of justice can be related to three possible types: procedural, distributive, or interactive. The procedural justice refers the decision processes, while the interactive justice is related to interpersonal treatments. The distributive justice refers to the rules regarding the allocated results, existing three identified rules: equity, equality and necessity (Filenga \& Siqueira, 2006). Particularly, there is an underlying expectation that procedural justice might improve chances of commitment to the implementation of agreements (Druckman \& Wagner, 2017). Rawls (1971) had already studied this type of justice, which deals with the perceptions of justice about the means adopted related to the decision process. In order to increase the level of commitment, managers are invited to enhance decision making process that can proportionate efficiency and consensus in group decision (Ganegoda \& Folger, 2015; Roberto, 2004). In this sense, Almeida et al. (2015) and Wibowo \& Deng (2013) point out that using methods and procedures for modeling the decision-making process, both individual and collective, makes the process rational, transparent and effective, which could render greater satisfaction and commitment to the agreement.

As an example, Govindan et al. (2017) used the multicriteria method PROMETHEE (Preference Ranking Organization Method for Enrichment Evaluations) for aiding group decision making process. The aggregation of the preferences of the decision-makers was based on the use of the Harsanyi's utilitarian principles and Rawls's egalitarian principles. The utilitarian principle states that the best group agreement would be the one that maximizes the sum or average of utilities. The egalitarian principle would be equivalent to the maximin principle, which aims to maximize utility among the least favored individual in the group. A ranking of commitment was constructed to minimize the distance of the individual rankings to the solution adopted by the group. However, the authors did not evaluate the commitment with the choice.

Recently, Leoneti (2016) developed a multicriteria method to support group decision making based on game theory principles. In the proposed method, a utility function allows modeling group multicriteria decision-making problems as games for solving the game using equilibrium solution concepts by taking into account the preferences of each individual. The perceived advantage of this method is that it does not require aggregations procedures as the classical multicriteria decision making methods, which allows evaluating strategic interaction within conflictive scenarios (Leoneti \& Ziotti, 2019).

The objective of this study is to evaluate how the commitment to agreements can be improved by the application of a group multicriteria method based on game theory and the analysis of the satisfaction and the sense of justice of the agents. The specific objectives were: (i) verifying the adherence of the solutions recommend by the method to those generated through negotiation; 
(ii) evaluating the sense of justice and satisfaction levels according to the final result, which was determined through a voting procedure for choosing between the method's solution and the agreement; (iii) analyzing how many agents changed their initial preferences in the search of the agreement; and (iv) analyzing a rationality deviation index to compare the method's solution and the agreement in terms of individual perspective.

\section{METHODOLOGY}

An experiment proposed in Leoneti and de Sessa (2017) that is based on the interpretation of the three phase model of Van De and Delbecq (1971) for group decision-making was adapted for the purpose of this research. The experiment is divided into the following phases: (I) an preliminary phase, where general information about the method (mostly with regards to the fact that it is based on game theory), and the instructions and rules of the experiment are presented; (II) a individual phase, in which: (i) it is presented a case to be solved in the form of a decision matrix; (ii) the participants rank criteria and alternatives of decision matrixes, according to their preferences; (III) a group phase, in which: (iii) each participant presents their alternatives' preferences and 15 minutes for negotiation is allowed, with two researchers reporting the negotiation process and calculating the solution based on the payoffs generated by the group multicriteria decision-making method; (iv) at the ending of negotiation the discloser of the solution is made simultaneously by the presentation of all calculated possible arrangements and their respective payoffs, and the group starts a brief discussion about the comparison between the negotiated solution and the solution provided by the method; and finally (IV) a final phase, in which: (v) after the considerations regarding the negotiated solution and the solution provided by the method, each participant presents his/her final decision in a secret manner by means of a ballot; (vi) the researchers disclose whether or not there was a commitment to the agreement by means of the verification of unanimity; (vii) if there was commitment (unanimity), the final decision was always the one negotiated by the group, independently of the fact that eventually the solutions of the method were equal to the negotiation process; (viii) if no consensus was verified, the final solution was proposed by the researchers obeying a random choice between the solution provided by the method (approximately $50 \%$ of the time) or an alternative different of both the solution provided by the method or the negotiated solution, the latter representing a top-down kind of decision that penalizes the fact that the group was not able to find and committing to a decision. Finally, similarly to the procedure of Leoneti and de Sessa (2017) each participant evaluated the final decision using two variables: sense of justice and satisfaction, both measured on a Likert type scale of five levels. The phases II, III and IV occurred three times, one for each of three case proposed. Figure 1 shows the possible outcomes that can be generated from the experiment procedures, henceforth called scenarios.

Summarizing, in "Scenario I" the group negotiated and managed to reach a consensus (all voted to keep the agreement made by the group), representing commitment to the final decision. In addition, the method was able to predict the decision negotiated. In "Scenario II" the group negotiated and managed to reach a consensus, creating commitment to the decision. However, 


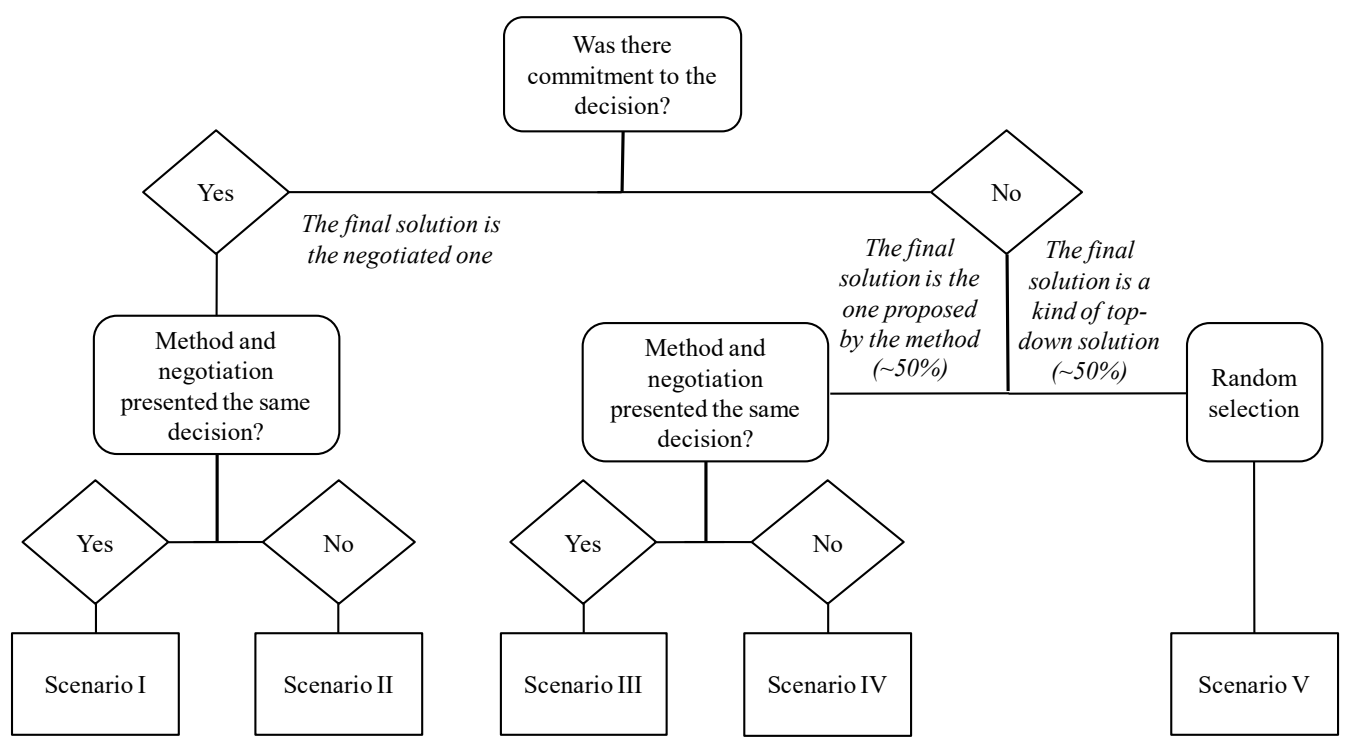

Figure 1 - Scenarios generated from the possible outcomes of the experiment.

the method was not able to predict the decision negotiated by the group. In both scenarios I and II, the final solution was always the one negotiated by the group. Conversely, in "Scenario III" the group failed to reach a consensus, that is, there was no commitment. However, the method was able to predict the decision negotiated by the group. In "Scenario VI" the group also failed to reach a consensus. Additionally, the method was not able to predict the decision negotiated by the group. Obeying a random criterion of $50 \%$ of the times, in both scenario III and IV the final solution, in this case forced by the researchers, was always the solution provided by the method. In the remaining $50 \%$ of the times, the final decision was also forced by the researchers, but always involving a different solution from that proposed by the method or the negotiated by the group, representing an external top-down kind of decision, deconstructing the collective decision-making process.

For data collection, 25 applications of the experiment were carried out between Apr/2017 and June/2018 in groups formed by five volunteers each, all students from the School of Economics, Business Administration and Accounting of University of São Paulo, in Ribeirão Preto, which were invited and them organized for participating in one application each time, totalizing the participation of 125 volunteers. At the beginning of each application, the volunteers received a form containing the decision matrices of three cases with short, medium and long term impact, respectively: (A) the choice a travel destination; (B) the choice a language course; and (C) the choice of the new president to a company, respectively, totalizing 75 negotiations. The three cases were not presented in the same order, to guarantee similar effects between the first, second and the last negotiation. All cases were structured as a decision matrix of five alternatives and eight criteria, including four natural criteria, which can be directly measure, and the remaining with constructed criteria, for which indirect measures based on subjective evaluations were used 
for their measuring. These matrix were balanced to grant that each alternative had at least one criterion with the highest score, and the value for each alternative, calculated through the average of the eight criteria, were the closest possible. Details of the three cases and their respective decision matrixes can be seen in the Appendix section.

In each application, the rankings of the criteria and alternatives provided by each agent (individual phase) were collected and inserted into an Excel spreadsheet containing the Ranking Order Centroid - ROC method (Barron \& Barret, 1996). The ROC method is a type of rankorder method, which applies a transformation of ranks into ratios. The calculation is given by the equation

$$
w_{i}=\frac{1}{n} \sum_{k=i}^{n} \frac{1}{k}
$$

where $n$ is the number of criteria, $i$ is the ith element in the ranking, and $k$ is used for calculate the weight of the ith element in the ranking.

Following, a non-cooperative game was modeled by the application of the utility function (Leoneti, 2016) that were also added to the Excel spreadsheet, which includes the calculation of the function $\pi_{d}: R_{+\rightarrow[0,1]}^{D}$ for all arrangements of alternatives that represents the payoff for an agent $d$ from the set of $D$-agents defined as

$$
\pi_{d}\left(x_{d}, x_{d \neq p}\right)=\prod_{d \neq p, p=1}^{D} \varphi\left(x_{d}, x_{p}\right) \cdot \varphi\left(x_{p}, I A_{d}\right)
$$

where $\pi_{d}\left(x_{d}, x_{d \neq p}\right)$ is the utility for the $d t h$ decision maker when considering swapping the alternative $x_{d}$ by the subset $x_{d \neq p}$ from the set of alternatives formed by the alternatives proposed by the $D-1$ remaining decision makers ${ }^{1}$, and $\varphi$ is given by the pairwise comparison function $\varphi: R_{+\rightarrow[0,1]}^{n}$ according to the equation

$$
\varphi\left(x_{d}, x_{p}\right)=\left[\frac{\alpha_{x_{d} x_{p}}}{\left\|x_{p}\right\|}\right]^{\delta} \cos \theta_{x_{d} x_{p}}, \text { and } \delta=\left\{\begin{array}{c}
1, \text { if } \alpha_{x_{d} x_{p}} \leq\left\|x_{p}\right\| \\
-1, \text { otherwise }
\end{array}\right.
$$

where $\alpha_{x_{d} x_{p}}=\left\|x_{d}\right\| \cos \theta_{x_{d} x_{p}}$ is the scalar projection of the vector $x_{d}$ onto the vector $x_{p}$, and $\left\|x_{p}\right\|=\sqrt{\left(x_{p}^{1}\right)^{2}+\left(x_{p}^{2}\right)^{2}+\ldots+\left(x_{p}^{n}\right)^{2}}$ is the norm of the respective vector with $n$ criteria. Intuitively, the utility function $\pi_{d}$ is defined therefore as the potential of the $d t h$ decision maker to swap $x_{d}$ to $x_{p}$, including their relativity with the ideal alternative $I A_{d}$ (the utopist alternative that is composed by the best scores of each $j=1,2, \ldots, n$ evaluation criteria).

In the light of Nash Program assumptions, which states that the solution of a non-cooperative game would converge to the same solution of a cooperative game if the former is modeled as an enlarged game that would contain the preplay interaction between agents that occur before the settle of a cooperative game, we used Nash bargaining solution, a type of cooperative solution concept with lower computational time demanding, for solving the game (Binmore, 1994). It was

\footnotetext{
${ }^{1}$ The version of the utility function presented in this paper does not consider the first factor as suggested in Leoneti (2016).
} 
assumed that the negotiation time provided to the participants would be appropriated for applying the concept of Nash Program for predicting the bargaining outcome. According to Binmore (1994), Nash (1950) found that the unique rational solution to the bargaining problem would be given by the maximization of the social welfare function

$$
N\left(\pi_{1}, \pi_{2}, \ldots, \pi_{D}\right)=\left(\pi_{1}-\xi_{1}\right)\left(\pi_{2}-\xi_{2}\right) \ldots\left(\pi_{D}-\xi_{D}\right)
$$

where $\xi_{d}$ are the status quo point that represents the outcome that each agent would receive if the negotiation would fail, in this case zero, and $\pi_{d}$ are the respective outcomes calculated by the application of the utility function. The procedure provides a unique solution, which was considered the method's solution.

Following, the rationality deviation index proposed in Leoneti and de Sessa (2017) was used to calculate the deviation of the Nash bargaining solution and to estimate the perception of the agents with regards to the group's solution. The rationality deviation index used in this research can be seen in equation

$$
\triangle_{e}=\frac{\bar{x}_{g}}{\bar{x}_{e}}-1
$$

where $\triangle_{e}$ is the rationality deviation index of the solution, $\bar{x}_{g}$ is the average payoff of the group choice and $\bar{x}_{e}$ is average payoff for the selected solution. If $\bar{x}_{g}$ is larger than $\bar{x}_{e}$ the ratio between these two numbers is greater than unity and therefore $\triangle_{e}$ will be positive. In this case, there was a deviation from the selected solution, but the group chooses a solution that provides, on average, higher payoffs to those involved, a Paretto improvement. On the other hand, if $\bar{x}_{g}$ is lower than $\bar{x}_{e}, \triangle_{e}$ will be negative, which means that the group choose a solution that provides, on average, lower payoffs than the method's solution.

Afterwards, it was used an exhaustive search algorithm for finding all pure Nash (1951) equilibria of the game and, in the presence of more than one Nash equilibrium, the utilitarian principle of Harsanyi, which seeks to maximize the sum or average of the individuals' utilities, was used as a social welfare ordering for selecting the best ranked equilibrium. It was used for validating the solution found by means of the Nash bargaining solution, since, according to Binmore (1994), if both solutions coincide, there is strong evidence that the cooperative solution concept is predicting correctly the outcome of the non-cooperative bargaining game.

\section{RESULTS AND DISCUSSION}

The method proposed in Leoneti (2016) was used to model the non-cooperative game, which was solved by the application of the Nash bargaining solution. The henceforth called "method" (the combined use of the utility function with the Nash bargaining solution concept) had presented the results through scenarios as shown in the table 1.

Among the 75 applications, there were 37 cases of commitments (scenarios I and II) and 38 without commitment (scenarios III, IV and V). This result was expected, given the complexity of establishing a collective decision. Regarding the specific objective of verifying the adherence 
Table 1 - Scenarios results.

\begin{tabular}{|c|c|c|c|c|}
\hline Scenario I & Scenario II & Scenario III & Scenario IV & Scenario V \\
\hline 20 & 17 & 7 & 13 & 18 \\
\hline
\end{tabular}

of the solutions supported by the method and those generated by negotiation, the method converged to the result of the negotiation in 31 cases (scenarios I, III and part of scenario V), which corresponds to about $47 \%$ of accuracy in predicting the results of the negotiation when participants reached an agreement. Considering randomness in the choice of five alternatives, $20 \%$ of chance for each one, the p-value for a binomial test in a sample of 75 cases would be lower than $0.0001 \%$, below the significance level of 5\%, rejecting the hypothesis that the method produces random predictions. It is also worthy to note that, considering only the cases where the commitment occurred (Scenarios I and II), the accuracy of the method is higher, about 54\%.

For evaluating the sense of justice and satisfaction according to the final result, it was calculated the averages of satisfaction and sense of justice per scenario, that is, the average of each agent per negotiation, given by the scale of one to five, where five was the highest value for reference, as suggested by Moore (2007). That sought to assess whether the sense of justice and satisfaction are greater when agreements are supported by some decision support method. In other words, it was evaluated if the use of a well-structured method can support group decision making process in an effective way, impacting positively the individuals' satisfaction (S) and sense of justice (SJ), which could directly impact the commitment to an agreement. Table 2 presents the results of the average of these variables per scenario.

Table 2 - Satisfaction (S) and sense of justice (SJ) average by scenario.

\begin{tabular}{|c|c|c|c|c|c|c|c|c|c|}
\hline \multicolumn{2}{|c|}{ Scenario I } & \multicolumn{2}{|c|}{ Scenario II } & \multicolumn{2}{c|}{ Scenario III } & \multicolumn{2}{|c|}{ Scenario IV } & \multicolumn{2}{|c|}{ Scenario V } \\
\hline S & SJ & S & SJ & S & SJ & S & SJ & S & SJ \\
\hline 4.83 & 4.87 & 4.26 & 4.49 & 4.56 & 4.72 & 3.77 & 3.86 & 3.63 & 3.69 \\
\hline
\end{tabular}

Comparing the scenarios I and II, where commitment was noticed and the method converged and did not converge to the negotiated agreement, respectively, satisfaction and justice indexes were higher for Scenario I, in which the solution of the method was the same of the negotiated one. In Scenario I, it can be noted that the method can provide improvements to the decision making process, which could explain the best levels of satisfaction and justice when compared to the other scenarios. Thus, when the group reached commitment (Scenario I and II), satisfaction and sense of justice were higher than the remaining scenarios, and higher for Scenario I, corroborating the affirmation that a well structured decision making process could influences the perception of justice and, consequently, the commitment to agreements made (Ganegoda \& Folger, 2015; Almeida et al., 2015; Wibowo \& Deng, 2013).

With regards to Scenario III, it has been revealed that there is, on the part of some participants, the intention to the breach of contract, which was identified by the lack of unanimity by the counting 
of the ballots. However, in this scenario, the negotiated alternative was the same suggested by the decision making method, which might suggest that the decision maker could still be committed to the decision implementation, since the sense of justice and satisfaction were greater when compared to Scenario II. Putting in another way, when the solution was negotiated, but it did not convince all agents about being the best agreement, the method acted as a way of validating the group's choice. This can be noticed since the sense of justice and satisfaction were greater on Scenario III when compared to Scenario II, where there was commitment with the negotiated decision, though without convergence with the method.

For the remaining scenarios, scenarios IV and V, it was expected that lower levels of satisfaction and a sense of justice would be observed, since these variables are important antecedents of commitment (Filenga \& Siqueira 2006, Druckman \& Wagner 2017). It can be seen from the comparison of scenarios IV and V that the effect on the sense of justice and satisfaction is very similar whether the decision is suggested by a method or by an individual who did not participated in the negotiation, similarly to a hierarchical superior, representing a decision exogenous to the group. However, slightly higher values were noticed in the scenario with support of the method (Scenario IV).

We may conclude that the union of an effective negotiation and a well structured group decision making process supported by a decision making method could minimize the effects of the breach of contract. This is an important result to the context of organizations, as Filenga and Siqueira (2006) and Li and Cropanzano (2009) have identified that the perception of justice is an important antecedent of organizational commitment, which justifies the use of support tools to increase the chances of commitment to the group decision. Regarding the difference between perceived satisfaction and sense of justice, Saha and Kumar (2017) stated that satisfaction is positively related to utility itself, and in this case it would not be possible to guarantee satisfaction to all agents when they are not having their maximum payoffs. In this way, it becomes evident that the levels of satisfaction and justice sense would be different and, in this particular case, it should be stressed that the levels of justice sense was slightly higher than the levels of satisfaction for all scenarios. Positive process evaluations great influence the sense of justice in the negotiating parties' attitudes towards the agreement, with implications for the implementation of the final group decision-making process (Li \& Cropanzano 2009; Druckman \& Wagner 2017).

It was also analyzed how many agents changed their most preferable alternative during the negotiation in the search of an agreement. Therefore, it was investigated the changes made by each agent through the comparison between their first ranked alternative settled in the individual phase and the alternative by them indicated in the ballot at the end of the third phase. It should be noticed that among the 75 applications performed, most individuals did not present changes from their most preferable alternative, including one case in which the negotiation was not necessary, since all agents chose the same alternative initially. It was verified that in $56 \%$ of the time the agents did not change their initial alternatives. When changes were observed, agents opted to swap their initial alternative to the alternative negotiated by the group in $76 \%$ of the time, which indicates a collaborative movement. Camerer (2011) and Charness and Sutter (2012) point out 
that due to the perception of justice a person may eventually choose to ensuring a fair outcome for those involved. That is, changing alternatives in favor to the group may be a result of the justice perception of the negotiation (Saha \& Kumar, 2017).

It was also applied the rationality deviation index proposed in Leoneti and de Sessa (2017) to analyze the agreement in terms of individual perspective, which results are summarized in Table 3. The index equals to zero indicates that the solution negotiated by the group is the same suggested by the method. In 31 negotiations there was convergence between these solutions and, among that, 20 presented commitment and 11 did not. It was noted that the sum of the payoffs' differences between the converged solution and the initial most preferable alternative of each agent was higher for the case where the index was equal to zero and the commitment occurred. For those 20 cases, the sum was around 0.53 , while for the 11 remaining it was around 0.05 , which indicates that there are more individuals losing than gaining in the latter. In general, when the decision-maker is faced with an amount below the average of the total amount, there is a sufficient evidence for injustice perceptions, causing rejection to the agreement ( $\mathrm{Li} \&$ Cropanzano, 2009). Therefore, despite the large number of cases in which the commitment did not occurred even with the convergence of the method's and the agreed decision, around $1 / 3$ of the total, the presence of larger looses could be the cause of the breach of contract, which is in accordance with the results found by Camerer (2011).

Table 3 - Rationality deviation index and commitment.

\begin{tabular}{|c|c|c|c|c|c|c|c|c|}
\hline Index & \multicolumn{2}{|c|}{ Index = 0 } & \multicolumn{2}{|c|}{ Index < 0 } & \multicolumn{2}{c|}{ Index $>0$} & \multicolumn{2}{|c|}{ No consensus in negotiation } \\
\hline \multirow{2}{*}{ Negotiations } & \multicolumn{2}{|c|}{31} & \multicolumn{2}{|c|}{27} & \multicolumn{2}{|c|}{8} & \multicolumn{2}{|c|}{9} \\
\cline { 2 - 9 } & 20 & 11 & 13 & 14 & 4 & 4 & N/A & 9 \\
\hline Commitment & Yes & No & Yes & No & Yes & No & Yes & No \\
\hline
\end{tabular}

Negative deviation index means that the agreement had average payoffs lower than the one provided by the Nash bargaining solution. It is interesting to note that the alternative chosen by the group were not related to the solution concept and this was reflected in slight higher number of breach of contract, since among of 27 cases, 14 times the group did not demonstrate commitment. Nonetheless, it is also interesting to note that there are cases in which groups maintained their commitment to alternatives that led to the lower average payoffs in relation to the Nash bargaining solution, in the belief that through commitment they would extract a better social result, as explained by Moore (2007). Positive deviation index would indicate that the Nash bargaining solution did not find the Pareto optimal solution. It was observed in the eight times that the group found a solution better to the proposed by the method. However, in the absence of the confirmation of the solution by the method, there were equal occurrences between commitment to agreement and breach of contract. In Table 4, the results of the rationality deviation index were also evaluated by using the sense of justice and satisfaction variables.

As expected by the prior results, the satisfaction and sense of justice were higher when the group matches the solution proposed by the method. In this case, one can conclude that the group, given 
Table 4 - Satisfaction (S) and Sense of Justice (SJ) average by deviation index result.

\begin{tabular}{|c|c|c|c|c|c|c|c|}
\hline \multicolumn{2}{|c|}{ Index $=0$} & \multicolumn{2}{c|}{ Index $<\mathbf{0}$} & \multicolumn{2}{c|}{ Index $>\mathbf{0}$} & \multicolumn{2}{c|}{ No consensus in negotiation } \\
\hline S & SJ & S & SJ & S & SJ & S & SJ \\
\hline 4.52 & 4.64 & 4.17 & 4.16 & 4.25 & 4.55 & 3.53 & 3.69 \\
\hline
\end{tabular}

the high level of satisfaction and sense of justice, may present greater chances to commitment. This corroborates previous results, since the levels of sense of justice were greater through negotiation with the method's support than when no agreement was reached. According to Druckman and Wagner (2017), the sense of justice principles starts from the negotiation process to the outcome and implementation of the decision. Finally, when the index was negative, the sense of justice and satisfaction were higher than for the case where the group did not find solution during the negotiation. It confirms that some method's support, such as the group multicriteria method used in this research, can make the decision-making process more robust, which can contribute to the implementation of the decision.

\section{CONCLUSIONS}

The main objective of this research was to evaluate commitment in group decision making process from the application of a group multicriteria decision making method based on game theory and the evaluation of the final solution by the sense of justice and satisfaction of the participants of a group decision making experiment. There were 125 participants involved in 25 applications of the experiment for negotiating three different cases, totalizing 75 negotiations.

Although a group multicriteria decision making method would hardly prescribe the final result of a negotiation process, as it was noticed in this research with around $41 \%$ of accuracy in predicting the outcome of the negotiation, it was observed that when commitment occurred and the method matched the negotiated solution, which corresponded to $54 \%$ of the time in this research, the highest levels of satisfaction and sense of justice were reported. This fact corroborates the literature that justifies improvements in the process of group decision making by using a wellstructured method to increase the chances of commitment to agreements, minimizing the chances of breach of contracts. In this research commitment occurred in $49 \%$ of the time. Conversely, when there was no commitment, levels of satisfaction and sense of justice were low, though they were significantly higher in the scenario where the solution proposed by the method matched the negotiated solution.

In the perspective of individuals, it was found that in $30 \%$ of the time a movement towards the agreement was made, thought it did not result in commitment in all the cases, since in around $35 \%$ of the time there was breach of contract by those who did not maintained their concession made. In this sense, it should be stressed that the method is also an important tool to reduce the chances of deviations from rationality in the decision-making process. 
Finally, it is also noteworthy that the Nash bargaining solution converged to the Nash equilibrium solution in $87 \%$ of the time in the situations which Nash equilibrium predicted correctly the bargaining outcome. Therefore, it indicates that the choice and use of the Nash bargaining solution was effective for solving the non-cooperative bargaining game proposed in this research, which is in accordance with the assumptions of Nash Program.

\section{ACKNOWLEDGMENTS}

To the undergraduate students from School of Economics, Business Administration and Accounting of University of São Paulo in Ribeirão Preto that participated as volunteers, to Karina Nomelini and Graciele Santos for assisting the invitation of the volunteers and the organization of the experiment sessions, to Coordenação de Aperfeiçoamento de Pessoal de Nível Superior CAPES for the Master's Scholarship in the Program DS-CAPES, and to São Paulo Research Foundation (FAPESP) for Regular Research Grant (2016/03722-5).

\section{References}

[1] De almeida A T, Cavalcante C A V, Alencar M H, Ferreira R J P, De AlmeidA-FIlHo A T \& GARCEZ T V. 2015. Multicriteria and multiobjective models for risk, reliability and maintenance decision analysis (Vol. 1). Springer International Publishing.

[2] BARron F H \& BARREtT B E. 1996. Decision quality using ranked attribute weights. Management Science $\mathbf{4 2}$.

[3] BAZERMAN M H \& MoORE D A. 2012. Judgment in managerial decision making. Wiley Global Education.

[4] Binmore K G. 1994. Game theory and the social contract: just playing (Vol. 2). MIT press.

[5] CAMERER C F. 2011. Behavioral game theory: Experiments in strategic interaction. Princeton University Press.

[6] Charness G \& SutTer M. 2012. Groups make better self-interested decisions. Journal of Economic Perspectives 26(3): 157-76.

[7] Cropanzano R, Fortin M \& KirK J F. 2015. How do we know when we are treated fairly? Justice rules and fairness judgments. In: Research in personnel and human resources management. Emerald Group Publishing Limited, pp. 279-350.

[8] DRUCKMAN D \& WAGNer L. 2017. Justice and fairness in negotiation. Group Decision and Negotiation, 26(1): 9-17.

[9] Filenga D \& Matias Siqueira M M. 2006. O impacto de percepções de justiça em três bases de comprometimento organizacional. Revista de Administração-RAUSP, 41(4). 
[10] Ganegoda D B \& Folger R. 2015. Framing effects in justice perceptions: Prospect theory and counter factuals. Organizational Behavior and Human Decision Processes 126: $27-36$.

[11] Govindan K, Kadziński M \& Sivakumar R. 2017. Application of a novel PROMETHEE-based method for construction of a group compromise ranking to prioritization of green suppliers in food supply chain. Omega 71: 129-145.

[12] HARSANYI J C. 1977. Rational behavior and Bargaining equilibrium in games and social situations, Cambridge University Press, Cambridge, UK.

[13] KeEney R L. 1982. Decision analysis: an overview. Operations research, 30(5): 803838.

[14] LEE C S. 2012. Multi-objective game-theory models for conflict analysis in reservoir watershed management. Chemosphere 87(6): 608-613.

[15] LeONETI A B. 2016. Utility function for modeling group multicriteria decision making problems as games. Operations Research Perspectives 3: 21-26.

[16] Leoneti A B \& De Sessa F. 2017. A Deviation Index Proposal to Evaluate Group Decision Making Based on Equilibrium Solutions. In: International Conference on Group Decision and Negotiation (pp. 101-112). Springer, Cham.

[17] Leoneti A B \& Ziotti V C. 2019. Modeling the Conflict Within Group Decision Making: A Comparison Between Methods that Require and Do Not Require the Use of Preference Aggregation Techniques. In: International Conference on Group Decision and Negotiation. Springer, Cham, pp. 57-64.

[18] Li A \& Cropanzano R. 2009. Fairness at the group level: Justice climate and intraunit justice climate. Journal of management 35(3): 564-599.

[19] MadANi K \& Hipel K W. 2011. Non-cooperative stability definitions for strategic analysis of generic water resources conflicts. Water resources management 25(8): 1949-1977.

[20] Miljkovic D. 2005. Rational choice and irrational individuals or simply an irrational theory: A critical review of the hypothesis of perfect rationality. The Journal of SocioEconomics 34(5): 621-634.

[21] Mislin A A, Campagna R L \& Bottom W P. 2011. After the deal: Talk, trust building and the implementation of negotiated agreements. Organizational Behavior and Human Decision Processes 115(1): 55-68.

[22] Moore D A. 2007. Not so above average after all: When people believe they are worse than average and its implications for theories of bias in social comparison. Organizational Behavior and Human Decision Processes 102(1): 42-58. 
[23] NASH J. 1951. Non-cooperative games. Annals of mathematics 286-295.

[24] NASH J. 1950. The bargaining problem. Econometrica 155-162.

[25] PARK Y, Song J H \& Lim D H. 2016. Organizational justice and work engagement: the mediating effect of self-leadership. Leadership \& Organization Development Journal 37(6): 711-729.

[26] RAWLS J. 1971. A theory of justice. Harvard University Press, Cambridge, MA.

[27] Roberto M.A. 2004. Strategic decision-making processes: Beyond the efficiencyconsensus trade-off. Group \& Organization Management 29(6): 625-658.

[28] SAHA S \& KUMAR S P. 2017. Influence of participation in decision making on job satisfaction, group learning, and group commitment: empirical study of public sector undertakings in India. Asian Academy of Management Journal 22(1).

[29] Van De A \& DelbecQ A L. 1971. Nominal versus interacting group processes for committee decision-making effectiveness. Academy of Management Journal 14(2): 203212.

[30] Wibowo S \& DENG H. 2013. Consensus-based decision support for multicriteria group decision making. Computers \& Industrial Engineering 66(4): 625-633.

\section{How to cite}

ZiotTi V C \& LEONETI A B. 2020. Improving commitment to agreements: the role of group decisionmaking methods in the perception of sense of justice and satisfaction as commitment predictors. Pesquisa Operacional, 40: e230300. doi: 10.1590/0101-7438.2020.040.00230300. 


\section{APPENDIX}

\section{Case 1: Choice of a travel destination}

In order to attract and retain customers, a travel agency created a promotion and a group of people won an "all-included" travel by the agency. The conditions were: the winners must travel together and the agency will cover the hotel (including breakfast) and travel expenses. Congratulations, you are one of the lucky ones! Considering that every winner has, at least, 12 days of vacation, you have to negotiate with the other winners the travel destination.

\begin{tabular}{|c|c|c|c|c|c|c|c|c|}
\hline Alternatives & \multicolumn{9}{|c|}{ Criteria } & \multicolumn{1}{c|}{} \\
\hline & 1 & 2 & 3 & 4 & 5 & 6 & 7 & 8 \\
\cline { 2 - 9 } & $\begin{array}{c}\text { Hotel } \\
\text { evaluation }\end{array}$ & $\begin{array}{c}\text { Traveling } \\
\text { duration }\end{array}$ & $\begin{array}{c}\text { Number of } \\
\text { nights }\end{array}$ & $\begin{array}{c}\text { Exchange } \\
\text { rate }\end{array}$ & Shopping & $\begin{array}{c}\text { Cultural } \\
\text { attractions }\end{array}$ & Nature & Infrastructure \\
\hline Destination A & 2,5 & $8 \mathrm{~h}$ & 4 days & $\mathrm{R} \$ 0,9$ & 5 & 3 & 7 & 8 \\
\hline Destination B & 3,5 & $2,5 \mathrm{~h}$ & 6 days & $\mathrm{R} \$ 3,1$ & 9 & 7 & 3 & 6 \\
\hline Destination C & 3 & $4 \mathrm{~h}$ & 7 days & $\mathrm{R} \$ 4,7$ & 4 & 5 & 9 & 7,5 \\
\hline Destination D & 5 & $13 \mathrm{~h}$ & 5 days & $\mathrm{R} \$ 3,3$ & 3 & 9 & 6 & 7 \\
\hline Destination E & 4 & $16 \mathrm{~h}$ & 8 days & $\mathrm{R} \$ 1,1$ & 6 & 8 & 5 & 5 \\
\hline
\end{tabular}

Hotel evaluation: Score from 1 to 5 about hotel evaluation in booking websites

Traveling duration (hours): Travel duration to the destiny

Number of nights: Number of nights included

Exchange rate: Exchange rate of the country's money in Brazilian reais according to the Central Bank's website

Shopping: Score from 1 to 10 to evaluate if the destiny is good for shopping

Cultural attractions: Score from 1 to 10 to determinate the presence of museums, theaters, restaurants, etc.

Nature: Score from 1 to 10 if the destiny has natural landscapes

Infrastructure: Score from 1 to 10 if it is safe in terms of sanitary conditions, traffic and etc.

\section{Case 2: Choice of an language school}

You and four other people won a scholarship for an English course paid by an English-language foundation. For that, it's necessary that all the winners choose the same school. Considering that all the winners live in the same neighborhood, you should negotiate with the others contemplated to decide in which school the group will enroll.

\begin{tabular}{|c|c|c|c|c|c|c|c|c|}
\hline Alternatives & \multicolumn{9}{|c|}{ Criterion } & \multicolumn{2}{c|}{} \\
\hline & 1 & 2 & 3 & 4 & 5 & 6 & 7 & 8 \\
\cline { 2 - 10 } & $\begin{array}{c}\text { Distance } \\
(\mathbf{k m})\end{array}$ & Courseware & Class size & Class hours & Infrastructure & $\begin{array}{c}\text { School } \\
\text { reputation }\end{array}$ & $\begin{array}{c}\text { Extra } \\
\text { activities }\end{array}$ & $\begin{array}{c}\text { Course } \\
\text { quality }\end{array}$ \\
\hline School A & $14 \mathrm{~km}$ & $\mathrm{R} \$ 450$ & 15 & $2 \mathrm{~h}$ & 10 & 6 & 4 & 9 \\
\hline School B & $7 \mathrm{~km}$ & $\mathrm{R} \$ 650$ & 12 & $3 \mathrm{~h}$ & 9 & 8 & 5 & 8 \\
\hline School C & $16 \mathrm{~km}$ & $\mathrm{R} \$ 590$ & 4 & $2,5 \mathrm{~h}$ & 8 & 7 & 9 & 7 \\
\hline School D & $6,5 \mathrm{~km}$ & $\mathrm{R} \$ 570$ & 8 & $6 \mathrm{~h}$ & 5 & 8 & 6 & 8 \\
\hline School E & $10 \mathrm{~km}$ & $\mathrm{R} \$ 300$ & 18 & $4 \mathrm{~h}$ & 7 & 9 & 8 & 5 \\
\hline
\end{tabular}

Distance $(\mathrm{km})$ : Distance between school and neighborhood

Courseware: Total cost of courseware in a year 
Class size: Average number of students per class

Class hours (Weekly): Hours of class and extra activities per week

Infrastructure: Score from 1 to 10 for installations, international platforms access, technology, etc.

School reputation: Score from 1 to 10 for market appreciation

Extra activities: Score from 1 to 10 about open events, group of studies, cultural activities, championships, etc.

Course Quality: Score from 1 to 10 about teacher's qualification and teaching methods.

\section{Case 3: Choice of a new CEO}

The owners of a company with egalitarian participation have to decide, among the employees, a new CEO to lead the company that is one of the leaders in the industry. Due to the contractual clauses, all owners must agree with the candidate. You are one of the owners. Therefore, you have to negotiate with the other owners who will be the new CEO.

\begin{tabular}{|l|c|c|c|c|c|c|c|c|}
\hline Alternatives & \multicolumn{9}{|c|}{ Criterion } \\
\hline & 1 & 2 & 3 & 4 & 5 & 6 & 7 & 8 \\
\cline { 2 - 10 } & $\begin{array}{c}\text { Professional } \\
\text { qualification }\end{array}$ & $\begin{array}{c}\text { Years of } \\
\text { company }\end{array}$ & $\begin{array}{c}\text { Years in } \\
\text { the area }\end{array}$ & $\begin{array}{c}\text { Leadership } \\
\text { positions }\end{array}$ & Ethic & $\begin{array}{c}\text { Adaptation } \\
\text { to change }\end{array}$ & Commitment & Professional \\
\hline Candidate A & 8 years & 7 years & 7 years & 3 roles & 10 & 4 & 6 & 9 \\
\hline Candidate B & 7 years & 4 years & 10 years & 3 roles & 9 & 9 & 4 & 8 \\
\hline Candidate C & 6 years & 6 years & 15 years & 4 roles & 8 & 7 & 7 & 4 \\
\hline Candidate D & 5 years & 8 years & 12 years & 7 roles & 7 & 8 & 8 & 4 \\
\hline Candidate E & 4 years & 10 years & 9 years & 6 roles & 5 & 7 & 10 & 7 \\
\hline
\end{tabular}

Professional qualification: Years of study after graduation

Years of company: Number of years the candidate works in the company

Years in the area: Number of years the candidate works in the same area of the company

Leadership positions: How many leaderships positions the candidate had worked (supervision, management, board, project leader)

Ethic: Score from 1 to 10 for ethical principles (integrity, transparency)

Adaptation to change: Score from 1 to 10 ease to changes in the work environment

Commitment: Score from 1 to 10 about fidelity and initiative

Professional influence: Score from 1 to 10 about external networking that can promote the company 